\title{
Atividade antimicrobiana dos extratos de folhas e ramos da Ilex paraguariensis A. St.-Hil., Aquifoliaceae
}

\author{
Bruno De Biasi, Neiva A. Grazziotin, Arno E. Hofmann Jr* \\ Departamento de Ciências da Saúde, Curso de Farmácia, Universidade Regional Integrada do Alto Uruguai e \\ das Missões, Campus de Erechim, Av. Sete de Setembro 1621, Prédio 12, 99700-000 Erechim-RS, Brasil
}

\begin{abstract}
RESUMO: Para avaliação da atividade antimicrobiana de Ilex paraguariensis foram utilizados seis microrganismos: Candida albicans, Escherichia coli, Proteus mirabilis, Pseudomonas aeruginosa, Staphylococcus aureus e Staphylococcus epidermidis. O método utilizado foi de difusão do disco. Foram adicionados em discos de papel filtro $10 \mu \mathrm{l}$ de extratos hidro-alcoólicos das folhas e ramos coletados de dois ambientes distintos, com e sem exposição ao sol. As placas foram incubadas a 35- $37^{\circ} \mathrm{C}$ por $24 \mathrm{~h}$. Os extratos inibiram levedura, bacilos gram-negativos e cocos gram-positivos, não mostrando atividade frente à Escherichia coli.
\end{abstract}

Unitermos: Ilex paraguariensis, erva-mate, atividade antimicrobiana, Aquifoliaceae.

\begin{abstract}
Antimicrobial activity of extracts of the leaves and branches of Ilex paraguariensis (erva-mate)". For the evaluation of the antimicrobial activity of Ilex paraguariensis six microorganisms were used: Candida albicans, Escherichia coli, Proteus mirabilis, Pseudomonas aeruginosa, Staphylococcus aureus and Staphylococcus epidermidis. In disks of filter paper $10 \mu 1$ of hydro-alcoholic extracts of the leaves and branches from two distinct environments were added, with and without sun exposure. The extracts have inhibited levedura, gram-negative bacillus and gram-positive cocos, with no activity to Escherichia coli.
\end{abstract}

Keywords: Ilex paraguariensis, erva-mate, antimicrobial activity, Aquifoliaceae.

\section{INTRODUÇÃO}

Pesquisas de atividade antimicrobiana utilizando extratos de plantas populares apresentam cada vez maior importância contra microrganismos patogênicos como Candida albicans, Escherichia coli, Proteus mirabilis, Pseudomonas aeruginosa, Staphylococcus aureus e Staphylococcus epidermidis (Pessini et al., 2003; Pereira et al., 2004; Aguiar et al., 2008; Coutinho et al., 2008; Michelin et al., 2008; Salvagnini et al., 2008; Bertucci et al., 2009; Silva Junior et al., 2009). Uma destas plantas é a Ilex paraguariensis A. St.-Hil., Aquifoliaceae (ervamate), que em estudo realizado por Gonçalves et al. (1995) apresentou atividade inibitória frente a microrganismos.

A erva-mate era consumida pelos indígenas que habitavam a região sul do Brasil antes mesmo da chegada dos colonizadores, sendo sua propriedade estimulante já conhecida (Evans, 1998). Pertence à família Aquifoleaceae e ao gênero Ilex, tem sua origem na América do Sul, nos países Argentina, Paraguai e Brasil, neste distribuído pelos estados do Mato Grosso, São Paulo, Paraná, Santa Catarina e Rio Grande do Sul. Apresenta uma maior produção na região sul do Brasil, especificamente no Rio Grande do Sul, devido ao consumo tradicional do chimarrão (Alikaridis, 1987; Bruneton, 1993; Esmelindro et al., 2002).
O uso da planta apresenta algumas contraindicações como em casos de ansiedade, taquicardia, hipertensão, gastrites, úlceras gastrintestinais e algumas doenças hepáticas (Bromatos, 2000).

A planta apresenta períodos alternados de crescimento, estagnando totalmente no inverno. A maior emissão de novos metâmeros ocorre de forma mais intensa no período primaveril (Rakocevic et al., 2006) sendo as metilxantinas presentes em maior concentração durante o verão (Schubert et al., 2006).

O perfil fitoquímico da Ilex paraguariensis apresenta várias classes incluindo flavonóides, terpenóides, metilxantinas, saponinas, taninos, carotenóides, aminoácidos, ácidos graxos, carboidratos, proteínas, glicídios, vitaminas e minerais (Alikaridis, 1987; Borille et al., 2005; Bortoluzzi, 2006; Brenelli, 2003; Ducat \& Quinàia, 2004; Filip et al., 2001; Gnoatto et al., 2005; Gnoatto et al., 2007; Reissmann \& Carneiro, 2004).

Análises e estudos sobre a erva-mate revelam diversas propriedades nutritivas e farmacêuticas tais como: antioxidante, antimicrobiana, diurética, digestiva, cicatricial e estimulante, conferindo um grande potencial de aproveitamento (Asolini et al., 2006; Filip et al., 2000; Gorzalczany et al., 2001; Gonçalves et al., 2005; 
Kowalczyk et al., 2006; Vidor et al., 2002).

Neste estudo, destinou-se interesse por ensaio antimicrobiano dos extratos de folhas e ramos com e sem exposição ao sol de Ilex paraguariensis, utilizando-se diferentes microrganismos.

\section{MATERIAL E MÉTODOS}

\section{Preparação do material vegetal}

A coleta das folhas e ramos com e sem exposição ao sol de Ilex paraguariensis, foi realizada no mês de janeiro de 2007, pelos pesquisadores, na propriedade de cultivo da Ervateira Barão, no município de Barão de Cotegipe (RS). As folhas e os ramos, dos dois ambientes, foram separados e submetidos a etapas de trituração e extração, em aparato de triturador de facas com auxílio de etanol sendo, posteriormente, filtrados. A solução filtrada foi concentrada e seca em evaporador rotatório à pressão reduzida e com temperatura inferior a $40{ }^{\circ} \mathrm{C}$. Anteriormente à avaliação da atividade antimicrobiana, preparou-se concentrações de $100 \mathrm{mg} / \mathrm{mL}$ e $50 \mathrm{mg} / \mathrm{mL}$ dos extratos em água.

\section{Atividade antimicrobiana}

Para a realização da atividade antimicrobiana foram utilizados seis microrganismos: Candida albicans ATCC 90028, Escherichia coli, Proteus mirabilis ATCC 25933, Pseudomonas aeruginosa ATCC 27853, Staphylococcus aureus ATCC 6538 e Staphylococcus epidermidis ATCC 12228.

Os microrganismos foram inoculados em agar nutriente, por $24 \mathrm{~h}$ a temperatura de $35{ }^{\circ} \mathrm{C}$. Após este período, preparou-se uma suspensão com os mesmos em solução fisiológica obtendo-se uma turvação equivalente ao padrão 0,5 da escala de Mac Farland, o que corresponde a aproximadamente $1,5 \times 10^{6} \mathrm{UFC} / \mathrm{mL}$. Uma alíquota de $100 \mu 1$ desta suspensão foi transferida para placa de Petri com Muller Hinton agar. O método utilizado foi de difusão do disco (Oplustil et al., 2000). Em cada placa de microrganismo semeado distribuiu-se discos de papel filtro Whatman ${ }^{\circledR}$ com $6 \mathrm{~mm}$ de diâmetro, contendo $10 \mu \mathrm{l}$ dos extratos. O procedimento foi realizado em triplicata.

Como controle positivo foram utilizados discos de antibióticos comerciais, variáveis de acordo com a espécie bacteriana. A seguir, as placas foram fechadas, invertidas e incubadas a $35-37^{\circ} \mathrm{C}$. Após $24 \mathrm{~h}$ de incubação realizou-se a leitura dos resultados, por meio da medição do diâmetro dos halos de inibição, incluindo os $6 \mathrm{~mm}$ dos discos de papel filtro. Os microrganismos foram considerados resistentes (R) aos extratos quando o halo de inibição apresentou-se inferior a $10 \mathrm{~mm}$.

\section{RESULTADOS E DISCUSSÃO}

Nas Tabelas 1 e 2 estão demonstrados os resultados do teste antimicrobiano dos extratos de folhas e ramos com e sem exposição ao sol nas concentrações de $100 \mathrm{mg} / \mathrm{mL}$ e $50 \mathrm{mg} / \mathrm{mL}$, respectivamente. Na tabela 3 estão apresentados os resultados dos testes de controle dos antibióticos comerciais.

Tabela 1. Atividade antimicrobiana dos extratos de Ilex paraguariensis, em concentração de $100 \mathrm{mg} / \mathrm{mL}$. R- Resistente e medida do halo de inibição apresentado em mm.

\begin{tabular}{lcccc}
\hline Microrganismos & $\begin{array}{c}\text { Extrato de folhas com } \\
\text { exposição ao sol }\end{array}$ & $\begin{array}{c}\text { Extrato de ramos com } \\
\text { exposição ao sol }\end{array}$ & $\begin{array}{c}\text { Extrato de folhas sem } \\
\text { exposição ao sol }\end{array}$ & $\begin{array}{c}\text { Extrato de ramos sem } \\
\text { exposição ao sol }\end{array}$ \\
\hline Escherichia coli & $\mathrm{R}$ & $\mathrm{R}$ & $\mathrm{R}$ & $\mathrm{R}$ \\
Proteus mirabilis & 14 & 17 & 11 & 20 \\
Pseudomonas aeruginosa & 15 & 17 & 11 & 18 \\
Staphylococcus aureus & 19 & 21 & 10 & 19 \\
Staphylococcus epidermidis & 13 & 11 & $\mathrm{R}$ & 15 \\
Candida albicans & 10 & 12 & $\mathrm{R}$ & 15 \\
\hline
\end{tabular}

Tabela 2. Atividade Antimicrobiana dos extratos de Ilex paraguariensis, em concentração de $50 \mathrm{mg} / \mathrm{mL}$. R- Resistente e medida do halo de inibição apresentado em mm.

\begin{tabular}{lcccc}
\hline Microrganismos & $\begin{array}{c}\text { Extrato de folhas com } \\
\text { exposição ao sol }\end{array}$ & $\begin{array}{c}\text { Extrato de ramos com } \\
\text { exposição ao sol }\end{array}$ & $\begin{array}{c}\text { Extrato de folhas sem } \\
\text { exposição ao sol }\end{array}$ & $\begin{array}{c}\text { Extrato de ramos sem } \\
\text { exposição ao sol }\end{array}$ \\
\hline Escherichia coli & $\mathrm{R}$ & $\mathrm{R}$ & $\mathrm{R}$ & $\mathrm{R}$ \\
Proteus mirabilis & 10 & 10 & $\mathrm{R}$ & 13 \\
Pseudomonas aeruginosa & $\mathrm{R}$ & $\mathrm{R}$ & $\mathrm{R}$ & $\mathrm{R}$ \\
Staphylococcus aureus & 10 & 15 & $\mathrm{R}$ & 12 \\
Staphylococcus epidermidis & 10 & 12 & $\mathrm{R}$ & 10 \\
Candida albicans & 10 & 10 & $\mathrm{R}$ & 14 \\
\hline
\end{tabular}


Tabela 3. Resultados dos testes de controle de antibióticos comerciais com relação a cada microrganismo, apresentando ao lado o halo de inibição.

\begin{tabular}{lc}
\hline Microrganismos & Controle sensível \\
\hline Escherichia coli & Ami 24, Cip 40, Ipm 30 \\
Proteus mirabilis & Ami 24, Gen 26 \\
Pseudomonas aeruginosa & Caz 30 \\
Staphylococcus aureus & Tet 28, Van 25, Eri 30 \\
Staphylococcus epidermidis & Cip 30, Rif 16, Van 12 \\
Candida albicans & Flu 15 \\
\hline
\end{tabular}

Ami- (amicacina $30 \mu \mathrm{g}$ ); Caz- (Ceftazidima $30 \mu \mathrm{g}$ ); Cip(ciprofloxacina $5 \mu \mathrm{g}$ ); Eri- (eritromicina $15 \mu \mathrm{g}$ ); Flu- (fluconazol $10 \mu \mathrm{g}$ ); Gen- (gentamicina $10 \mu \mathrm{g}$ ); Ipm- (imipenem $10 \mu \mathrm{g}$ ); Rif(rifampicina $5 \mu \mathrm{g}$ ); Tet- (tetraciclina $30 \mu \mathrm{g}$ ); Van- (vancomicina $30 \mu \mathrm{g})$.

Os extratos da Ilex paraguariensis, em concentração de $100 \mathrm{mg} / \mathrm{mL}$ (Tabela 1), demonstraram diferentes halos de inibição para os diferentes microrganismos, o que pode ser atribuído à variação da composição química qualitativa e/ou quantitativa. Os extratos, em concentração de $50 \mathrm{mg} / \mathrm{mL}$ (Tabela 2), apresentaram halos de inibição inferiores aos demonstrados na concentração anterior, sendo para Candida albicans a menor redução, as demais informações obtidas assinalam uma resposta dependente da concentração.

Os quatro extratos da Ilex paraguariensis, folhas e ramos com e sem exposição ao sol, não apresentaram atividade antimicrobiana frente à bactéria gram-negativa Escherichia coli. Segundo Pessini et al. (2003), este fato poderia ocorrer pela presença de uma membrana mais externa que impossibilitaria a entrada de determinados compostos e/ou de enzimas capazes de quebrar as moléculas invasoras, porém isto não foi corroborado, pois os mesmos extratos apresentaram atividade contra as bactérias gramnegativas, Pseudomonas aeruginosa e Proteus mirabilis. Isto nos informa a existência de características específicas da Escherichia coli que a tornaram resistentes aos extratos.

O extrato dos ramos sem exposição ao sol apresentou maiores halos de inibição aos diferentes microrganismos, seguido pelo extrato dos ramos com exposição ao sol. Staphylococcus aureus foi o microrganismo mais sensível aos extratos com exposição ao sol, enquanto Proteus mirabilis foi o mais sensível aos extratos sem exposição ao sol.

Ramos sem exposição ao sol foi o extrato que apresentou melhor atividade antifúngica.

O extrato de folhas sem exposição ao sol (100 $\mathrm{mg} / \mathrm{mL}$ ), mostrou os menores halos de inibição, sendo o único extrato que apresentou resistência frente a todos os microrganismos, na concentração de $50 \mathrm{mg} /$ $\mathrm{mL}$, informando que neste os constituintes químicos, responsáveis pela atividade antimicrobiana, estão ausentes ou presentes em baixas concentrações.

Gonçalves (2005), em estudo antimicrobiano com extratos hidro-alcoólicos das folhas de erva-mate $(100 \mathrm{mg}$ / $\mathrm{mL}$ ), demonstrou atividade contra Staphylococcus aureus, Staphylococcus spp. coagulase negativa e ausência de atividade contra Escherichia coli, Proteus mirabilis e Pseudomonas aeruginosa. Estes resultados divergem parcialmente aos verificados pelo nosso grupo, que encontrou atividade contra $P$. mirabilis e $P$. aeruginosa, isto pode ter ocorrido provavelmente pela época de coleta, separação entre folhas e ramos e exposição ou não ao sol.

Os resultados indicam que a atividade antimicrobiana de Ilex paraguariensis sofre interferência pela exposição ou não ao sol e apresentam diferença entre as atividades dos extratos hidro-alcoólicos de folhas e ramos, estando nestes a maior atividade.

\section{AGRADECIMENTOS}

Agradecemos à Universidade Regional Integrada do Alto Uruguai e das Missões/URI- Campus de Erechim, pelo apoio financeiro e à Ervateira Barão pelo fornecimento do material vegetal.

\section{REFERÊNCIAS}

Aguiar JS, Costa MCCD, Nascimento SC, Sena KXFR 2008. Atividade antimicrobiana de Lippia alba (Mill.) N. E. Brown (Verbenaceae). Rev Bras Farmacogn 18: 436440.

Alikaridis F 1987. Natural constituents of Ilex paraguariensis. $J$ Ethnopharmacol 20: 121-144.

Asolini FC, Tedesco AM, Carpes ST, Ferraz C, Alencar SM 2006. Atividade antioxidante e antibacteriana dos compostos fenólicos dos extratos de plantas usadas como chás. Braz J Food Technol 9: 209-215.

Bertucci A, Olivaro C, Silva PA, Ramos D, Cerdeiras MP, Vázquez A 2009. Initial antimicrobial activity studies of plants of the riverside forests of the southern Uruguay River. Rev Bras Farmacogn 19: 20-25.

Borille WMA, Reissmann BC, De Freitas SJR 2005. Relação entre compostos fitoquímicos e o nitrogênio em morfotipos de erva-mate (Ilex paraguariensis A. St. Hil.). B. Ceppa 23: $183-198$

Bortoluzzi ALM, Pasqualatto RPR, Guesser G, Cardozo Jr EL, Donaduzi CM, Mitsui M 2006. Quantificação de metilxantinas e compostos fenólicos em amostras de erva-mate (Ilex paraguariensis A. St. Hil.). $4^{\circ}$ Congreso Sudamericano de la Yerba Mate $-4^{\circ}$ Reunión Técnica de la Yerba Mate; $2^{\circ}$ Exposición de Agronegocios de la Yerba Mate. Posadas, Argentina.

Brenelli SCE 2003. A extração de cafeína em bebidas estimulantes - uma nova abordagem para um experimento clássico em química orgânica. Quim Nova 26: 136-138.

Bromatos SL 2000. Fitoterapia: Vademecum de Prescripción. Plantas Medicinales. 3.ed. Barcelona: Masson. 
Bruneton J 1993. Elementos de Fitoquímica y de Farmacognosia. Paris: Technique et Documentation.

Coutinho HDM, Costa JGM, Siqueira-Júnior JP, Lima EO 2008. In vitro anti-staphylococcal activity of Hyptis martiusii Benth against methicillin-resistant Staphylococcus aureus-MRSA strains. Rev Bras Farmacogn 18 (Supl.): 670-675.

Ducat G, Quinàia OS 2004. Avaliação do teor de minerais da Ilex paraguariensis da região centro-oeste do estado do Paraná. Rev Cien Exat Nat 6: 31-42.

Esmelindro MC, Toniazzo G, Waczuk A, Dariva C, Oliveira D 2002. Caracterização físico-química da erva-mate: Influência das etapas do processamento industrial. Cien Tecnol Aliment 2: 199-204.

Evans WC 1998. Trease and Evan's Pharmacogosy. 14.ed. Londres: WB Saunders Company, p. 403.

Filip R, Lotito SB, Ferraro G, Fraga CG 2000. Antioxidant activity of Ilex paraguariensis and related species. Nutr Res 20: 1437-1446.

Filip R, López P, Giberti G, Coussio J, Ferraro G 2001. Phenolic compounds in seven south American Ilex paraguariensis. Fitoterapia 72: 774-778.

Gnoatto SCB, Schenkel EP, Bassani VL 2005. HPLC method to assay total saponins in Ilex paraguariensis aqueous extract. J Braz Chem Soc 4: 723-726.

Gnoatto SCB, Bassani VL, Coelho GC, Schenkel EP 2007. Influência do método de extração nos teores de metilxantinas em erva-mate (Ilex paraguariensis St. Hil., Aquifoliaceae). Quim Nova 2: 304-307.

Gonçalves AL, Filho AA, Menezes H 2005. Estudo comparativo da atividade antimicrobiana de extratos de algumas árvores nativas. Arq Inst Biol 3: 353-358.

Gorzalczany S, Filip R, Alonso MR, Mino J, Ferrero G, Acevedo C 2001. Choleretic effect and intetinal propulsión of "maté" (Ilex paraguariensis) and its substitutes or adulterantes. J Ethnopharmacol 75: 291-294.

Kowalczyk EC, Valduga TA, Hofmann Jr. EA, Roman SS 2006. Efeito do extrato de Ilex paraguariensis (Erva-Mate) no reparo tecidual de feridas em ratos. $4^{\circ}$ Congreso $\mathrm{Su}$ damericano de la Yerba Mate $-4^{\circ}$ Reunión Técnica de la Yerba Mate; $2^{\circ}$ Exposición de Agronegocios de la Yerba Mate. Posadas, Argentina.

Michelin DC, Sannomiya M, Figueiredo ME, Rinaldo D, Santos LC, Souza-Brito ARM, Vilegas W, Salgado HRN 2008. Antimicrobial activity of Byrsonima species (Malpighiaceae). Rev Bras Farmacogn 18 (Supl.): 690-695.

Oplustil CP, Zoccoli CM, Tobouti NR, Sinto SI 2000. Procedimentos básicos em microbiologia clínica. São Paulo: Sarvier, p. 169.

Pereira RS, Sumita TC, Furlan MR, Jorge AOC, Ueno M 2004. Atividade antibacteriana de óleos essenciais em cepas isoladas de infecção urinária. Rev Saude Publ 38: 326328.

Pessini GL, Holetz FB, Sanches NR, Cortez DAG, Dias Filho BP, Nakamura CV 2003. Avaliação da atividade antibacteriana e antifúngica de extratos de plantas utilizadas na medicina popular. Rev Bras Farmacogn 13: 21-24.

Reissmann CB, Carneiro C 2004. Crescimento e composição química de erva-mate (Ilex paraguariensis St. Hil.), transcorridos oito anos de calagem. Floresta 34: 381386.

Rakocevic M, Medrado MJS, Lucambio F, Valduga TA 2006. Caracterização de crescimento do caule da erva-mate (Ilex paraguariensis St. Hil.) cultivada em dois ambientes luminosos contrastantes. $4^{\circ}$ Congreso Sudamericano de la Yerba Mate - $4^{\circ}$ Reunión Técnica de la Yerba Mate; $2^{\circ}$ Exposición de Agronegocios de la Yerba Mate. Posadas, Argentina.

Salvagnini LE, Oliveira JRS, Santos LE, Moreira RRD, Pietro RCLR 2008. Avaliação da atividade antibacteriana de folhas de Myrtus communis L. (Myrtaceae). Rev Bras Farmacogn 18: 241-244.

Schubert A, Zanin FF, Pereira DF, Athayde ML 2006. Variação anual de metilxantinas totais em amostras de Ilex paraguariensis A. St. - Hil. (Erva-Mate) em Ijuí e Santa Maria, Estado do Rio Grande do Sul. Quim Nova 29: 12331236.

Silva Junior IF, Cechinel Filho V, Zacchino SA, Lima JCS, Martins DTO 2009. Antimicrobial screening of some medicinal plants from Mato Grosso Cerrado. Rev Bras Farmacogn 19: 242-248.

Vidor AM, Ruiz PC, Moreno VS, Floss AP 2002. Variabilidade Genética em um Ensaio de Progênies de Erva-Mate (Ilex paraguariensis St. Hil.). Cien Rural 32: 583-584. 